\title{
Elke dag telt!
}

Citation for published version (APA):

Roekaerts, P. M. H. J. (2014). Elke dag telt! Maastricht University. https://doi.org/10.26481/spe.20141114pr

\section{Document status and date:}

Published: 14/11/2014

DOI:

10.26481/spe.20141114pr

Document Version:

Publisher's PDF, also known as Version of record

\section{Please check the document version of this publication:}

- A submitted manuscript is the version of the article upon submission and before peer-review. There can be important differences between the submitted version and the official published version of record.

People interested in the research are advised to contact the author for the final version of the publication, or visit the DOI to the publisher's website.

- The final author version and the galley proof are versions of the publication after peer review.

- The final published version features the final layout of the paper including the volume, issue and page numbers.

Link to publication

\footnotetext{
General rights Owners
rights.

- You may freely distribute the URL identifying the publication in the public portal. please follow below link for the End User Agreement:

www.umlib.nl/taverne-license

Take down policy

If you believe that this document breaches copyright please contact us at:

repository@maastrichtuniversity.nl

providing details and we will investigate your claim.
}

Copyright and moral rights for the publications made accessible in the public portal are retained by the authors and/or other copyright owners and it is a condition of accessing publications that users recognise and abide by the legal requirements associated with these

- Users may download and print one copy of any publication from the public portal for the purpose of private study or research.

- You may not further distribute the material or use it for any profit-making activity or commercial gain

If the publication is distributed under the terms of Article $25 \mathrm{fa}$ of the Dutch Copyright Act, indicated by the "Taverne" license above, 
dr. P.M.H.J . Roekaerts Faculty of Health, Medicine and Life Sciences

\section{Elke dag telt!}




\section{"Elke dag telt!"}

Mijnheer de Rector Magnificus

Geacht College van Bestuur

Geachte Decaan, Vice-decaan en overige leden van het Bestuur van de Faculty of Health, Medicine and Life Sciences

Geacht Bestuur van het MUMC

Geachte collega's en medewerkers van het MUMC

Zeer gewaardeerde vrienden en toehoorders

Lieve familie

Voordat er sprake was van medische afdelingen Intensive Care - zoals we die nu kennen in de ziekenhuizen - werden de ziekste patiënten er al tezamen op één zaal gelegd. Omdat de zorg op deze zalen uiteraard erg intensief was, werd gesproken van Intensive Care, intensieve zorg. Deze intensieve zorg werd er geleverd door toegewijde Intensive Care verpleegsters. Naar de geschiedenis van de Geneeskunde kijkend valt steeds weer op dat jonge Intensive Care verpleegsters met veel gedrevenheid, compassie en kennis, de zorg voor de meest zieke patiënten telkens weer op een hoger plan brachten en daarmee de Intensive Care Geneeskunde in belangrijke mate mee hielpen ontwikkelen. Ik wil hier daarom dan ook een hommage brengen aan de vrouw in de gezondheidszorg. Ik zal dat doen door in het kort iets over het leven en werk van twee Intensive Care verpleegsters te vertellen.

Florence Nightingale studeerde aanvankelijk wiskunde, geïnspireerd door de Vlaamse wetenschapper Alphonse Quetelet, en daarna verpleegkunde. Na het uitbreken van de Krimoorlog in 1853 vroeg de Britse regering haar om in een ziekenhuis in Istanbul te starten met de inzet van verpleegsters bij de verzorging van Britse soldaten. Wat Florence hier voor mekaar kreeg, veelal ondanks maximale tegenwerking door de mannelijke militaire authoriteiten en doktoren, is onvoorstelbaar. Ik geef hier slechts een aantal van haar verwezenlijkingen aan:

1. De ziekste patiënten moesten bij de zusterpost gelegd worden, zodat ze continu konden bewaakt worden. Wellicht was dit de eerste vorm van opschaling van monitoring. 
2. Patiënten met een ontsteking of infectie mochten niet op dezelfde plaats verblijven als patiënten zonder ontsteking. Wellicht was dit de eerste vorm van isolatie.

3. Ook s'nachts moest er regelmatig naar patiënten gekeken worden. Met een lamp liep zij de verpleegafdelingen langs en kreeg daarbij de naam "The lady with the lamp". Wellicht was dit de eerste vorm van $24 / 7$ zorg.

4. Zij vond het pooldiagram uit en bracht de mortaliteitscijfers en de oorzaken ervan in haar ziekenhuis precies in kaart. Wellicht de eerste vorm van wetenschappelijk onderzoek naar de outcome van patiënten. Zij ontdekte hierbij dat de kans op overlijden 7 maal groter was in het ziekenhuis aan een ziekte dan op het slagveld aan een verwonding. Haar hypothese dat dit te wijten was aan slechte hygiëne werd bevestigd door het feit dat in geen tijd de mortaliteit zakte van $60 \%$ naar $42 \%$ door aangepaste hygiënemaatregelen en door de volledige herbouwing van de rioleringen en watervoorzieningen in haar ziekenhuis onder haar aansturing. Indien Florence nog leefde, zou ik haar met trots kunnen mededelen dat de Inspectie voor de Gezondheidszorg recent in ons ziekenhuis heeft vastgesteld dat wij nu ook steeds vaker onze handen beginnen te wassen.

Florence heeft het eerste zorgconcept geformuleerd bestaande uit een metaparadigma van de volgende vier kennisgebieden:

1. De Mens. Vanuit een holistische kijk op de mens behandelt men niet alleen de ziekte, maar ook de patiënt.

2. De Omgeving. De omgeving moet als volgt ingesteld worden: goede ventilatie, schone lucht, schoon water, warmte, rust, goed licht en een goede afvalverwerking.

3. De Gezondheid. Gezondheid is niet alleen dat je niet ziek bent, maar ook dat je in staat bent om al je mogelijkheden te benutten.

4. De Verzorging. Het doel van de verzorging is om de patiënt in de beste conditie te krijgen zodat de natuur zijn helende werking kan verrichten. Naar dit metaparadigma van Florence kijkend, ziet u meteen waar de MUMC visie op zorg en missie vandaan komen.

Florence heeft meer dan 200 publicaties op haar naam staan, schreef het eerste leerboek voor verpleegkunde en richtte de eerste verpleegsterschool op. Zij was Fellow van de Royal Statistical Society, erelid van the American Association of Statistics en ontving diverse onderscheidingen waaronder als 
eerste vrouw de Orde van Verdienste van Edward VII.

Mary Borden was een oorlogsvrijwilligster uit Chicago, die tijdens de Groote Oorlog, nu 100 jaar geleden, naar de Flanders Fields, in Roesbrugge bij leper, trok om er een veldhospitaal in te richten. Dit was een dermate intelligent, goed-doordacht concept dat haar methode overal navolging kreeg. Zij ontving voor haar werk de "Croix de Guerre" en de "Légion d'honneur" onderscheidingen.

Mary schreef over de verschrikkingen en het leed van de oorlog in het boek "The forbidden zone". Deze beschrijvingen kregen veel kritiek van de gevestigde maatschappij, die meestal een ander beeld ophing over het oorlogsgebeuren. Publicatie van haar boek werd dan ook tegengehouden tot in 1929. Het boek van Mary Borden is een wonder van proza, poëzie, mémoires en tablaux vivants. Zij beschrijft de droefheid van de oorlog, de vernietiging van menselijk leven, de hopeloosheid, de verspilling en de gekte. Ik lees voor u een fragment uit haar boek voor:

There are no men here, so why should I be a woman? There are heads and knees and mangled testicles. There are chests with holes as big as your fist, and pulpy thighs, shapeless; and strumps were legs once were fastened. There are eyes - eyes of sick dogs, sick cats, blind eyes, eyes of delirium; and mouths that cannot articulate; and parts of faces - the nose gone, or the jaw. There are these things, but no men; so how could I be a woman here and not die of it? Sometimes, suddenly, all in an instant, a man looks up at me from the shambles, a man's eyes signal or a voice calls "Sister! Sister!". Sometimes suddenly a smile flickers on a pillow, white, blinding, burning, and I die of it. I feel myself dying again. It is impossible to be a woman here. One must be dead.

Het is verheugend te constateren dat de laatste jaren steeds vaker vrouwen hogere functies bekleden binnen en buiten de organisatie van de 
gezondheidszorg. Maar, zoals wel vaker gebeurt, dreigt nu echter ook weer een overshoot te gaan plaatsvinden: zo werd enkele weken geleden - op 18 september - beslist dat ook vrouwen lid mogen worden van de golfclub St Andrews, de bakermat van het golf. Gekker moet het echt niet meer gaan worden.

In het algemeen wordt de ontwikkeling van de Intensive Care geneeskunde gerelateerd aan de polio-epidemie begin jaren '50 in Denemarken, waarbij vele patiënten moesten beademd worden met een ijzeren long. Vanaf de tweede wereldoorlog ontstonden postoperatieve bewakingsafdelingen, de huidige Recoveries, waaruit rond de jaren '70, de eerste IC afdelingen ontstonden.

In Maastricht werd de IC opgericht op 6 april 1972. U ziet achter mij de registratie van onze eerste IC opnames. Met deze handmatige registraties zijn we gestopt na de invoer van het electronisch ziekenhuis informatie systeem, het SAP. U gelooft het vast niet, maar meerdere van onze medewerkers vinden deze boeken met geschreven data handzamer dan het SAP - system against people.

De professionalisering van de Intensive Care geneeskunde bestaat nog maar pas een tiental jaren en IC-geneeskunde is dus nog een heel jong specialisme. In Nederland worden thans jaarlijks ongeveer 25.000 patiënten langer dan 48 uur met uiteenlopende aandoeningen opgenomen op een intensive care afdeling. Hiervan worden er 18.500 levend uit het ziekenhuis ontslagen.

Sepsis, of bloedvergiftiging, is een van de belangrijkste oorzaken van sterfte op een afdeling Intensive Care. Achter mij ziet u hoe de mortaliteit van $35 \%$ in tien jaar tijd gezakt is naar onder de $20 \%$. Alhoewel wij als intensivisten natuurlijk allemaal blij zijn met het feit dat overleving na een IC-opname sterk verbeterd is, hebben wij verzuimd om te kijken in welke mate daarbij de kwaliteit van leven - kortere en langere tijd na een IC-behandeling - behouden is gebleven. De laatste paar jaren verschenen er sporadisch internationaal enkele verontrustende rapporten die weergeven dat de lange-termijns kwaliteit van leven na een IC-behandeling verre van goed te noemen is.

Twee jaar geleden vond in de Verenigde Staten een eerste stakeholders 
conferentie plaats over de lange-termijnsuitkomsten na een IC behandeling. $\mathrm{Er}$ werd toen besloten de term "post intensive care syndroom" of PICS te gebruiken om nieuwe of verergerende fysieke, cognitieve en mentale gezondheidsproblemen te beschrijven die optreden na een intensive care behandeling bij overlevers en hun familie.

Neuromusculaire zwakte blijkt de belangrijkste fysieke beperking te zijn na een IC opname en de term IC-gerelateerde zwakte is thans omschreven als een specifieke post-IC aandoening. Deze zwakte treedt geschat op bij $40-60 \%$ van de ex-IC-patiënten en kan een paar jaren aanhouden. Dagelijkse activiteiten zoals het zich verzorgen, aan- en uitkleden, eten, zich wassen of wandelen zijn daarbij haast niet meer mogelijk. $U$ begrijpt de enorme belasting die dit met zich meebrengt, niet alleen mentaal voor de patiënt, maar ook voor zijn familie of verzorgers.

De cognitieve stoornissen die optreden blijven lang bestaan en de psychiatrische aandoeningen zijn veelal depressie, angst en het posttraumatisch stress syndroom. Deze stoornissen in de hersenfunctie veroorzaken problemen bij meer dan $40 \%$ van de patienten die op een IC verbleven en duren veelal een jaar, maar bij sommige patiënten blijven deze stoornissen bestaan. De meest voorkomende problemen zijn: zich iets niet kunnen herinneren, geen aandacht aan iets kunnen besteden, geen problemen kunnen oplossen, niets kunnen organiseren, of iets complex zoals een bankoverschrijving niet meer kunnen uitvoeren. $U$ begrijpt dat deze problemen een terugkeer in een normaal en professioneel leven haast onmogelijk maken. Ook andere mentale problemen komen vaak voor zoals slaperigheid of slapeloosheid, nachtmerries, schuwheid, angst, akelige herinneringen, depressies, droefheid, gebrek aan levensvreugde, verschrikkelijke visioenen en symptomen van post-traumatische stress. Ex-IC patiënten vertonen vaak persoonlijkheidsveranderingen en zijn vaak kwaad en lastig. De familie denkt veelal dat dit te wijten is aan de frustratie van de patiënt aangaande de traagheid van zijn herstel, maar in werkelijkheid vormt het een frequent onderdeel van de mentale stoornissen die horen bij het PICS. Verschrikkelijke herinneringen aan een IC-verblijf die niet hebben plaatsgevonden kunnen door de patiënt niet onderscheiden worden van herinneringen die wel echt hebben plaatsgevonden. Dit is uitermate traumatiserend voor de patiënt. Ik geef $u$ twee recente voorbeelden uit onze eigen praktijk die maanden na een 
IC-opname het leven van twee van onze ex-IC patiënten nog extreem bleven belasten: een eerste patiënte dacht dat er een verpleegkundige rondliep die haar thuis ging komen vermoorden, een tweede zag zichzelf voortdurend in een brandende oven geschoven worden. Deze angstwekkende beelden zouden kunnen samenhangen met allerhande manipulaties aan het lichaam en bepaalde radiologische onderzoeken tijdens de IC-opname.

Wij vinden dat er dringend hoog moet ingezet worden op de volgende drie aspecten van het postintensive care syndroom:

1. Het onder de aandacht brengen van het bestaan van het PICS, dat helaas te weinig bekend is in de gemeenschap als een wel omschreven syndroom.

2. De barrières opheffen die een goede zorg voor IC-overlevers en hun familie in de weg staan:

Een eerste barrière is het niet systematisch evalueren van de gezondheidstoestand van een IC-overlever. Het is dringend nodig dat er hierover data vanuit Nederland beschikbaar komen. Het in kaart brengen van deze post-IC problemen via het invullen van een vragenlijst na 6 maanden, na 1 jaar en zelfs later, kan een goed beeld geven van de conditie van een patiënt na een IC-verblijf. Wij zijn bezig met het opzetten van een studie om de kwaliteit van leven gedurende langere tijd na een IC-opname te volgen. Hier ligt ook een taak voor de ziektekostenverzekeraars. Immers, wanneer we aan de hand van post-IC data zouden kunnen vaststellen welke patiënten na een IC-opname de ergste klachten en beperkingen behouden, zou ons dat helpen om beter de patiënten te selecteren waarbij behandeling op een IC zinvol is. Het zou de zorg beter, efficiënter, goedkoper en menselijker maken.

Een tweede barrière is de onbekendheid van het syndroom bij artsen.

Een derde barrière is het niet goed overdragen van medische gegevens via checklijsten doorheen de verschillende stappen die een patiënt doorloopt na een IC-opname.

Een vierde barrière is het niet bestaan van case-managers die overlevers de eerste twee jaren na hun ontslag uit de IC regulier systematisch blijven vervolgen.

Een vijfde barrière is het niet bestaan van het PICS in de medische nomenclatuur en de ziektekostenverzekering.

Een zesde barrière is het niet-bestaan van een uitgestippeld revalidatietraject voor intensive care overlevers. 
3. Ten derde is het belangrijk dat research wordt opgezet om het nieuwe klinische syndroom PICS beter in kaart te brengen. Er is een gebrek aan basale en translationele research om post-intensive care beperkingen beter te begrijpen om alzo tot optimale preventie en behandeling van het PICS te komen.

De grootste uitdaging in de Intensive Care geneeskunde vandaag is om trachten te begrijpen hoe deze lichamelijke zwakte en mentale stoornissen tot stand komen en hoe we ze kunnen voorkomen, een plaats geven, draaglijker maken voor patiënt en familie en optimaal behandelen.

Het beeld dat de beste IC-zorg kan geleverd worden door een patiënt langdurig in een kunstmatig coma te houden met behulp van allerhande opium-achtige pijnstillers en slaapmiddelen en hem daarbij kunstmatig te beademen leeft nog steeds bij velen. De aangetaste orgaanfuncties van de patiënt zouden daarbij tijdens deze rustperiode maximaal kunnen herstellen.

Recent werd echter ingezien dat post-IC spierverval wel eens goed zou kunnen samenhangen met de spierrust tijdens de IC-opname en dat de post-IC optredende hersenstoornissen wel eens goed zouden kunnen samenhangen met het toedienen van allerhande pijn- en slaapmedicatie die op de hersenen inwerken en waarbij de patiënt zijn georiënteerdheid in tijd en plaats komt te verliezen tijdens de IC-opname.

Wij zijn er dan ook van overtuigd dat de globale IC-aanpak van patiënten anders moet en dat via het terugdringen van overdreven rust en van overdreven gebruik van medicijnen met inwerking op de hersenen we het PICS syndroom in ernst en voorkomen kunnen verminderen. Dit vereist echter een belangijke cultuuromslag bij elke IC-medewerker. Om dit te bewerkstelligen zijn we blij dat het MUMC+ operational excellence programma als hulpmotor fungeert om multidisciplinair te werken aan deze continue verbetering die optimale klantwaarde en minimale verspilling beoogt.

Onze Operational Excellence bundel heeft als naam "The MUMC Intensive Care Sixpack' en is een bundeling van de best beschikbare 'evidence' met betrekking tot voorkomen, behandelen en optimaliseren van zes met mekaar verweven verbeterpunten die de ernst en het voorkomen van het PICS na een IC-opname kunnen terugdringen. 
Het eerste luik uit onze sixpack is pijn.

Klassiek werden er op een IC altijd vrij veel op de hersenen inwerkende pijnstillers gegeven van de familie van morfine-achtigen om er toch maar zeker van te zijn dat de patiënt geen pijn had en goed tot rust kon komen. Het gevolg van deze werkwijze was dat de patiënt zijn hersenen werden gedempt, hij niet meer kon communiceren en elke oriëntatie in plaats en tijd verloor. Hierdoor werd de kans op het optreden van delirium goter. Bij een delirium heeft een patiënt veelal angstwekkende hallucinaties of wanen die levensecht lijken. Omwille van de hoog-gedoseerde medicatie bleef de patiënt ook lang beademd en immobiel liggen, met spierverval als gevolg. $U$ ziet meteen de relatie tussen teveel centrale pijnstilling en de laattijdige hersenstoornissen en spierzwakte. In het huidige sixpack programma meten we de ernst van de pijn aan de hand van meerdere meetinstrumenten zoals o.a. de VAS en de CPOT waardoor we de patiënt de juiste hoeveelheid pijnmedicatie kunnen geven en niet meer veel te veel. Tevens hanteren we het principe van "analgosedatie eerst": dat betekent het toedienen van een pijnstiller met enig rustgevend effect vooraleer specifieke rustgevende medicatie toe te dienen. Door deze werkwijze te hanteren blijven de patiënten wakkerder, zijn communicatiever, ontwikkelen ze minder delier en zijn ze meer actief en beweeglijk.

Een tweede luik van onze sixpack is het bestrijden van angst en onrust bij onze opgenomen patiënten.

De IC is uiteraard voor de meeste patiënten een traumatiserende omgeving waar men zieke en comateuze patiënten verbonden ziet met diverse electronische apparatuur en waar er voortdurend allerhande alarmsignalen afgaan. Vaak kunnen de patiënten daarbij suboptimaal communiceren omwille van medicatie of omwille van een buisje tussen de stembanden of omwille van de ernst van de ziekte. Vroeger werd zeer veel sedatiemedicatie gegeven omdat men de patiënt zoveel als mogelijk kalmte en rust wilde geven. Sedatiemedicatie is angstwerende, rustgevende en slaapverwekkende medicatie. Door deze medicatie echter was de patiënt nog minder georiënteerd in tijd en plaats, ontwikkelde hij derhalve vaker een delier en was wegens de rustgevende medicatie meer immobiel met spierverval als gevolg. De benzodiazepines, een groep van medicijnen verwant aan valium, zijn met name beduchte verwekkers van delier. Onze sixpack insteek voor wat betreft sedativa is de volgende: minder is beter en vermijd daarbij zoveel als mogelijk 
benzodiazepines. Gelukkig zijn er zeer goede alternatieven voor de benzodiazepines. Propofol werd voor het eerst in Nederland als sedatiemiddel op de IC in Maastricht gebruikt en over gepubliceerd door de onderzoeksgroep Roekaerts-Huyge-de Lange. Ook het middel dexmedetomidine is een uitstekend alternatief voor benzodiazepines en is geassocieerd met een afname van de incidentie van delier op een IC. Zowel dierexperimenteel alsook klinisch werd dit middel voor het eerst gebruikt in Nederland hier in Maastricht door de onderzoeksgroep Roekaerts-Lawrence-Willigers-Prinzen en de Lange. Ook de selectieve serotonine-heropnameremmers of SSRI's worden vermoedelijk te weinig gebruikt op IC's om situationele angst te bestrijden. Binnen onze sixpack methodiek wordt de sedatiemedicatie zo gestuurd dat de patiënt comfortabel en zonder stress is maar wel alert en coöperatief. Dit met behulp van een score, de RASS-score, die de diepte van sedatie weergeeft. Deze geringere sedatie brengt veel extra communicatieve taken mee voor IC-medewerkers en familieleden om de patiënt te begeleiden: vertellen hoe het verloop van zijn ziektetoestand is, wat er die dag staat te gebeuren, welke dag en tijd het is, praatjes maken voor zover mogelijk over ditjes en datjes, een bepaald dagritme aanhouden, rustpauzes inlassen, het dag-nachtritme met geluid en duisternis respecteren enzovoort. Ook de familie moet actief bijdragen aan het georiënteerd blijven houden van de patiënt: praat over familiezaken, kennissen en gebeurtenisjes, herhaal vaak de dag, tijd en plaats, breng foto's en geliefde voorwerpen van thuis mee, lees iets voor aan het bed, vraag aan het IC-team hoe je de patiënt kan helpen met zijn lichamelijke bedoefeningen. Op onze IC kan elke patiënt beschikken over een dagboek waarin hijzelf , familie en de ICmedewerkers dingen kunnen opschrijven. Dit dagboek helpt de patient later, na de IC-opname, om beter te begrijpen wat er allemaal gebeurd is, om het beter te verwerken, herinneringen te ordenen en werkt bewezen tegen het ontstaan van posttraumatische stress.

\section{Het derde luik van onze sixpack is het delirium.}

Het optreden van een delier op een IC is soms te wijten aan de ziekte van de ICpatiënt, maar vaak hangt het delier samen met overmatig gebruik van morfine preparaten, benzodiazepines en andere medicijnen die op de hersenen inwerken en met een daarbijhorend verlies bij de patiënt van zijn oriëntatie in plaats en tijd. De patiënt weet daarbij niet waar hij is, waarom hij er is, en in welke tijdsperiode zich dit allemaal afspeelt. $U$ begrijpt dat dit stress, onrust en 
angst met zich meebrengt. Het vroeg herkennen en behandelen van delier is thans mogelijk omdat er een score is ontwikkeld om te bezien of de patiënt zich in een delier bevindt. Dit laat toe om sneller te behandelen. Het optreden van delier tijdens de IC-opname is geassocieerd met de post-IC psychische, mentale en cognitieve stoornissen. Het optreden van delier en het behandelen van delier laat vroege mobilisatie en lichaamsoefeningen niet toe, waardoor ook het spierverval en de latere lichamelijke beperkingen bevorderd worden. Voorkomen van delier is ook nu hier weer de boodschap door beperking van de psychotrope farmaca, maximale support door IC-medewerkers en familie, en optimalisatie van omgevingsfactoren om de patient alert en georiënteerd te houden.

Een vierde luik is ademen.

In de klassieke intensive care zorg was het tot voor kort nog de norm om erg zieke patiënten in kunstmatig coma te brengen met benzodiazepines en opiaten en ze te beademen middels een buisje in de luchtwegen met een beademingsmachine. Absolute rust was een voorwaarde om te kunnen herstellen van een zware infectie of andere bedreigende ziekte. Maar ook hier geldt: rust roest. Net dit overmatige medicatiegebruik, het rusten zonder lichaamsoefening en het beademen waarbij de patiënt zijn ademhalingsspieren en zijn middenrifspier niet meer hoeft te gebruiken, liggen zoals gesteld aan de basis van het spierverval en de slechte uitkomst voor wat betreft kwaliteit van leven later, na de IC-opname. Elke dag hoort een test plaats te vinden om te kijken of de patiënt spontaan kan ademen en wannneer de patiënt er aan toe is, moet snel overgeschakeld worden naar spontane ademhaling.

Een vijfde luik is het snel beginnen met lichaamsoefeningen en mobilisatie. We weten thans uit wetenschappelijk onderzoek dat verzwakking en atrofie van de lichaamsspieren bij rust razendsnel gaat en dat de duur van de bedrust bij een IC-opname consistent geassocieerd is met spierzwakte gedurende minstens 24 maanden na de opname en dat vroege mobilisatie en fysiotherapie de enige bewezen therapieën zijn die het fysieke en psychische functioneren van IC-overlevers verbetert. Wij streven er binnen onze IC naar om onze patiënten te mobiliseren binnen 48 uur na IC - opname. Dit kan uiteraard alleen maar goed plaatsvinden bij patiënten die wakker, alert en coöperatief zijn. Sedatie en pijnstilling en eventuele delierbehandeling moeten daarom gedoseerd zijn naar juist genoeg, en niet naar veel te veel. Op de foto 
ziet $u$ een van onze patiënten die een verwoeste longfunctie had en daardoor zuurstof in het bloed kreeg toegediend buiten het lichaam, terwijl hij toch in bed ligt te fietsen.

Het zesde en laatste luik van onze sixpack bundel is het voorkomen en tijdig bestrijden van een teveel aan water in het lichaam van de patiënt. Vaak zien we dat patiënten op een IC teveel vocht vasthouden in het lichaam. Dit vele vocht is soms een gevolg van het ziek zijn en de ontstekingen van de patiënt, maar vaak ook te wijten aan het onnodig veel toedienen van infuusvocht aan de patiënt of het niet agressief genoeg uit het lichaam halen van dit overtollige water met plasmedicatie of een kunstnier. Angst om hiermee de nieren te beschadigen krijgt dikwijls onterecht meer aandacht dan de vochtbalans van de patiënt. Echter, teveel vocht in organen betekent dat deze minder goed kunnen functioneren. Refererend naar wat we willen bereiken met onze sixpack bundel interesseert ons hier met name het oedeem in de longen waardoor de patiënt minder makkelijk zelf kan ademen en het oedeem in de hersenen waardoor de patiënt onrust, delier en cognitiestoornissen ontwikkelt. Met andere woorden, de waterhuishouding speelt een essentiële rol in het kunnen effectueren van de sixpack bundel.

Dames en heren, ik heb u onze sixpack bundel voorgesteld. Op deze dia ziet $u$ waar wij het woord sixpack vandaan hebben gehaald: in deze conditie zouden wij graag wat vaker onze patiënten willen ontslaan. Dit is uiteraard een utopie.

Alle zes elementen van deze bundel hangen samen, kunnen mekaar versterken, en zijn gebaat bij een geïntegreerde multidisciplinaire aanpak. Het uiteindelijke doel van deze bundel is om door maximaal te focussen op het behoud van alertheid en georiënteerdheid van de patiënt - door maximale aandacht te besteden aan preventie en behandeling van pijn, angst, delier en vochthuishouding - deze patiënt sneller zelf te kunnen laten ademen en lichaamsoefeningen te laten verrichten. Dit moet leiden tot een kortere verblijfsduur op de IC, en een kortere verblijfduur is geassocieerd met verbetering van de overleving. Elke dag telt! Een dag langer op de IC betekent meer kans op delier en meer kans op spierverval. Dit hangt samen met psychische stoornissen en spierzwakte die aan kunnen houden tot jaren na een IC opname. Ook hier geldt dus: elke dag telt! 
Op deze dia ziet $u$ het multidisciplinaire team dat betrokken is bij onze sixpack aanpak. Zonder goed afgesteld teamwork kan een dergelijk project niet slagen.

Elke dag tijdens het ochtendrondje wordt de hersen-GPS doorgenomen door het behandelend team waarbij de 6 elementen van de sixpack aan bod komen: hoe is de patiënt hier geraakt, waar is de patiënt nu en waar gaat patiënt naar toe? Met deze systematiek trachten we te voorkomen dat ook maar 1 dag zou verloren gaan in de optimalisatie van het sixpack beleid, want, zoals gezegd: elke dag telt!

Niet onbelangrijk om te vermelden is dat deze omslag in beleid rekening houdt met de maatschappelijke evoluties van minder geld en minder arbeidskrachten in de zorg. Door onze sixpack kunnen we de turn-over van patiënten op een IC vergroten. Daarbij leveren wij klantgerichte, duurzame, toegankelijke en betaalbare zorg. Via deze sixpack helpen we mee onze maatschappelijke opdracht te realiseren: met het beschikbare budget per saldo meer gezondheidswinst opleveren.

Opname van een patiënt op de IC brengt een familiecrisis met zich mee. Familieleden zijn bezorgd en verward en besteden daardoor nog weinig aandacht aan hun eigen gezondheid. Het Intensive Care team vraagt de familie om beslissingen te nemen over belangrijke en overrompelende zaken. Hierdoor ontwikkelen tot $30 \%$ van familieleden van IC-patiënten zelf mentale gezondheidsproblemen zoals depressie, angst en posttraumatische stress symptomen. Hoe kan u, wanneer u ooit in de situatie terechtkomt dat 1 van uw familieleden op een intensive care afdeling wordt opgenomen, voorkomen dat u zelf aan symptomen van het post-intensive care syndroom gaat lijden? Allereerst en meest belangrijk moet u goed voor uzelf zorgen. Dit kan niet genoeg benadrukt worden. Aan de behoeften van je zieke familielid tegemoet komen is een belangrijk onderdeel van zijn behandeling, maar uw behoeftes zijn net zo belangrijk. Indien u zich goed voelt, hebt $u$ de fysieke en emotionele kracht om uw zieke familielid te ondersteunen en u daarbij zelf goed te voelen. Eet goed, neem voldoende lichaamsbeweging en zoek ondersteuning. Elk ziekenhuis heeft case managers, sociale werkers en pastorale diensten. Neem de tijd om het ziektebeeld van uw familielid te begrijpen en de behandelmogelijkheden ervan. Deze kennis zal u helpen om beslissingen te 
nemen, om zelfvertrouwen te hebben bij de beslissingen die u moet nemen en zal uw stress verminderen. Stel vragen, praat vaak met verpeegkundigen en artsen en overleg op reguliere tijdstippen met de medische IC case-manager die uw geliefde begeleidt. Hou een dagboek bij en bespreek dit met uw case manager zodat $u$ voor uzelf helder krijgt wat er allemaal gebeurt en hoe $u$ daar op reageert. Hiermee helpt u uzelf en ook het medisch team in het zo goed als mogelijk herkennen en respecteren van de patiënt zijn wensen, waarden en voorkeuren. Participeren in de zorg voor de patiënt is een andere manier om uw familielid te ondersteunen en stress te verminderen. Het verzorgend team van uw familielid kan u activiteiten voorstellen die u met uw familielid kan doen.

Alhoewel de intensivist steeds meer taken krijgt buiten de muren van de IC, zoals binnen het spoedinterventieteam, het reanimatieteam, de IC-polikliniek, en het interklinisch transport, ligt zijn core business bij de behandeling van de kritiek zieke patiënt op een intensive care afdeling. Als academische IC kunnen we terecht trots op zijn onze euregionale samenwerking met Genk, Aken en de regio Zuidoost-Nederland.

In de regio ZuidoostNederland werken de intensive Care afdelingen van 10 ziekenhuizen nauw samen binnen het samenwerkingsverband ICUZON. Het is voor mij een voorrecht om voorzitter van ICUZON te zijn en tezamen met mijn staf de regiefunctie te kunnen voeren van de IC-zorg in deze regio. Een van onze stafleden werkt tevens in het SJG Weert als medisch manager van de afdeling Intensive Care. Zelf ben ik tevens hoofd van de Intensive Care afdeling van het Laurentius ziekenhuis te Roermond. Met dit ziekenhuis vormen we met de intensivisten een personele unie, waarbij uitwisseling van intensivisten plaatsvindt. Dit is de 'best practice' om kwaliteit van IC-zorg binnen een regio te borgen.

Naast een opleiding tot intensivist in het MUMC, vervult de IC binnen de medische opleiding van de UM een aantal belangrijke onderwijsrollen. Tevens lopen jaarlijks een twintigtal medische studenten hoog-gewaardeerde klinische en wetenschappelijke stages op onze IC. Daarnaast heeft de afdeling Intensive Care een volledig onderwijsblok IC-technologie uitgewerkt voor de studenten Bio Medische Technologie aan de Technische Universiteit Eindhoven (TU/e). 
De research van de afdeling IC werd in 2010 versmald naar twee thema's : thema 1 omvat de cardiovasculaire research gefocust op hemostase en stolling enerzijds en koppeling micocirculatie en macrocirculatie anderzijds. Thema 2 omvat metabole research gefocust op infectie-inflammatie enerzijds en metabolisme en voeding anderzijds. Onze wetenschappelijke output ligt daarbij thans om en bij de $35 \mathrm{~W}-1$ publicaties op jaarbasis en er zullen twee promoties plaatsvinden in 2015 en twee in 2016. Daarnaast lopen er nog een aantal onderzoeksprojecten die afdelingsgebonden zijn: moeilijke ontwenning van de beademing, risicostratificatie bij transport van patiënten, en telemedicine.

Samen met partners uit Finland, België, Duitsland en Spanje hebben we een groot intensive care telemedicine project opgezet middels een belangrijke FP-7 Europese grant. Niet alleen zal dit project leiden naar een geografische uitbreiding van onze regiefunctie als academische IC van niveau 3 , maar ook zal telemedicine belangrijk worden in het thematisch ingericht ziekenhuis van de nabije toekomst om kritiek zieke patiënten die verspreid doorheen het ziekenhuis liggen te monitoren vanuit een centrale cockpit door telemedicineartsen.

Hiermee ben ik toegekomen aan het dankwoord.

Het is de verdienste van velen dat ik deze functie hier vandaag mag aanvaarden. Het is dan ook haast unfair om slechts enkelen met name te noemen. Toch ga ik het in zeer beperkte mate doen. Mensen die me kennen zullen wel beseffen dat het niet in mijn aard ligt om iemend tekort te doen. In Leuven ben ik prof van de Walle en prof van Aken dankbaar omdat ze mijn interesse in de Anesthesiologie en Intensive Care hebben gestimuleerd tijdens mijn studentenjaren.

In Leiden ben ik prof Spierdijk, prof Jack van Kleef en prof de Lange dankbaar voor een fantastische opleiding tot anesthesioloog-intensivist. Ik heb warme herinneringen aan de hartchirurgen prof Brom, prof Quaghebeur en prof Brutel. Mijn IC-stages mocht ik lopen in Leiden bij prof Feuth, in den Haag bij dr Vink en en in het Leidse beademingscentrum bij prof Van Zanten. Prof de Lange betrok mij in de opiaten-research en hielp mij de nodige internationale contacten dienaangaande te leggen met o.a. met prof Stanley uit Salt Lake City, prof Stanski uit Los Angeles en prof Moore uit Chicago. 
Al vele jaren werk ik als medisch specialist in Maastricht als anesthesioloog en als intensivist. Het opzetten in het azM van een cardiochirurgische operatieafdeling en cardiochirurgische intensive care was voor mij een van mijn mooiste klinische uitdagingen. Samen met prof Penn, de hartchirurg, en met mijn collegae dr. Lawrence en dr. Smets wisten we al vrij snel een hoogkwalitatieve afdeling op te zetten, uiteraard met de hulp en inzet van vele artsen en verpeegkundigen. Prof de Lange en prof Prinzen hebben mijn researchontwikkeling in het MUMC+ verder begeleid. Dierexperimenteel myocardischemie onderzoek met Frits Prinzen hebben eerst tot mijn promotie geleid en later tot belangrijke klinische studies en promoties van dr. Lawrence, dr. Willigers en dr. Heijmans, waarbij ik als co-promotor fungeerde. Jarenlang was ik actief binnen het netwerk van prof Mangano uit San Francisco en participeerde in internationaal onderzoek naar perioperatieve myocardischemie. Dit heeft mijn epidemiologische inzichten merkbaar helpen ontwikkelen. Dank ben ik ook verschuldigd aan prof Durieux uit Virginia en aan prof Maarten van Kleef die mij de mogelijkheid boden om me een tijd volledig toe te leggen op algemene Intensive Care zorg. Zeer veel dank ben ik verschuldigd aan prof Jan Harm Zwaveling die mij gemotiveerd en gestimuleerd heeft om de Intensive Care van het MUMC+ verder academisch uit te bouwen. Alle collegae, en met name een fantastisch team stafleden Intensive Care, verpleegkudigen, secretaresses en medewerkers waarmee ik in team-verband heb samengewerkt en nog samenwerk wil ik bedanken voor deze fijne samenwerking. Het college van Bestuur van de Universiteit Maastricht dank ik voor de benoeming. Mijn RVE-management, prof Nijhuis en mevrouw ter laak, de heer Peeters en de Raad van Bestuur van het MUMC, de decaan prof Scherpbier en de vice-decaan prof De Vries verdienen mijn maximale dank voor hun vertrouwen in mij en de ongoing gewaardeerde ondersteuning.

Ik vind het elke dag opnieuw weer een eer en een voorrecht dat ik in het MUMC+ kan komen werken. Wat is er mooier dan op een veilige en mooie plek op aarde in een warme omgeving je medemens trachten bij ziekte weer gezond te maken en meer nog, zoals ook in de MUMC+ missie staat, de gezondheid van mensen uit deze regio eerst en vooral optimaal te houden en ziekte trachten te voorkomen door gezond te leven.

Ik wil nog mijn familie en ouders bedanken. 
Mijn vader, hier docerend aan de Katholieke Universiteit van Leuven in het jaar 1943, was voor mij dagelijks opnieuw de visualisatie van de eed van Hippocrates. Dit heeft mijn professionele instelling uitermate gevormd.

En last but not least: degenen die mij het meest na aan het hart zijn: Monika, Anouk, Esmée en Nona. Uiteindelijk draait het gewoon om jullie, Anouk, Esmée en Nona. Ik heb jullie zien opgroeien, al was het soms tussen de bedrijven door, van baby's tot volwassenen om trots op te zijn. Jullie zijn nu aan het uitzwermen. Gelukkig kan ik nog steeds volhouden dat ik het druk heb op het werk, want verfkwasten en verhuiswagens zijn niet zo mijn ding. Monika, je bent al 31 jaar mijn geliefde partner. Ik kan na 31 jaar partnership niets mooier zeggen dan dit: Monika, je bent daarnaast ook al 31 jaar mijn beste vriend.

Ik heb gezegd. 